\title{
LONGITUDINAL MOTION DUE TO ACTION OF TUNNEL THRUSTERS
}

\author{
Maciej Reichel \\ Ship Handling Research and Training Centre \\ Foundation for Safety of Navigation and Environment Protection, Poland
}

\begin{abstract}
Tunnel thrusters are propulsion and active control devises that provide a side force, or transverse thrust, to support mooring operations or position keeping. They shorten the time of manoeuvring, reduce the cost of towage and since inception, manoeuvrability specifically in ports has become a lot easier. Tunnel thrusters can either be operated manually or with the help of Dynamic Positioning systems which makes it even more efficient.

Theoretically, the transverse force due to tunnel thruster action should generate only lateral and rotational motion. Therefore, it is typical and a common practice during manoeuvring simulations that the longitudinal motion due to the action of tunnel thrusters is neglected. Nevertheless, the experience of masters and pilots shows that some longitudinal motion due to the action of tunnel thrusters appears.

This paper shows some examples of turning manoeuvres carried out with bow thrusters only, i.e. no additional control devices or tug assistance have been used. The manoeuvres have been carried with minimal possible initial longitudinal nor lateral speed. Model tests have been done with the use of large manned models of VLCS, PCTC and LNG carrier, which differ in hull shape, dimensions and shape coefficients.

Results obtained from the tests confirm that the motion caused by bow thruster besides rotational and lateral motion consists additionally of longitudinal motion. Analysis of the combination of motions due to the action of tunnel thrusters have been done and some rationale for this phenomenon has been presented. Additionally a short analysis of position of pivot point during tunnel thruster test has been carried out.
\end{abstract}

Keywords: VLCS, PCTC, LNG carrier, manned models, free running model tests

\section{INTRODUCTION}

Maritime sector is very important when analysing corridors of goods transportation. It is due to its effectiveness, relatively low environmental impact and price competitiveness. Therefore, to explore even more the economy of scale, ships become larger actually every year. On the other hand, port infrastructures do not follow the increase of ship dimensions and issues like safety of port manoeuvres become more and more significant and challenging.

Taking into account increasing ships dimensions, and thus decreasing manoeuvring space, the risk of any damage to vessels or port infrastructure is instantly growing and all possible steps should be taken to minimise this risk. Most important safety improvement aids, e.g. training of seamen, implementation of navigational aids and planning of harbour operations are primarily based on the simulation of ship motion. Therefore, modelling of ship motions during port manoeuvres, i.e. at slow speed in constrained space becomes to be essential. Different necessary aspects are taken into account when improving simulations of motions, e.g. wall effect on the hydrodynamic forces induced by the propellers and thrusters during berthing and unberthing (AbramowiczGerigk, 2007) or more precise description of manoeuvring forces at slow speed for azimuth thrusters (Reichel, 2017).

The same attention should be paid to the forces generated by tunnel thrusters, not only during berthing and unberthing, i.e. with very small rotational velocity, but also during other port manoeuvres with larger rotational velocities. In such 
situations, e.g. manoeuvres in turning basins, additional factors reported by masters and pilots, like increasing longitudinal velocity due to the action of bow thruster should be taken into account. It can be however seen, that this longitudinal motion caused by the action of tunnel thrusters is neglected during simulations and analysis. Brix (1983) and especially Chislett and Björheden (1966) explained in details side force and turning moment generated by lateral thruster with the loss of effectiveness induced by the forward speed of the ship. They did not report however, on the possible occurrence of longitudinal force or velocity caused by the action of tunnel thrusters.

It has to be noted that the described phenomena is not always necessary to be taken into account during port manoeuvres analyses. When simulating crabbing motion, the influence of bow or stern thruster action on the longitudinal motion may be neglected (Quadvlieg and Toxopeus, 1998). In such a case the rotational speed is minimal and the possible longitudinal motion, caused by tunnel thruster action, is compensated by main propulsion system working in "ahead and balancing" propellers mode.

Nevertheless, some researchers have noticed the phenomenon of longitudinal motion due to the action of bow thruster. Artyszuk $(2003,2010)$ presented some analytical results of forward velocity increase calculations, where a conclusion on the increase of surge velocity with decreasing yaw velocity has been given. The responsibility for such a motion has been put on the centrifugal force in rotational motion. Some attempt to this issue has been also made by Gierusz (2016). The author suggests to introduce a weak surge force proportional to the longitudinal velocity of the ship and to a specific empirical parameter, without however information on increase of the longitudinal velocity from the action of bow thruster at zero surge speed.

This paper makes an attempt to a systematic research on the issue of the influence of tunnel thrusters action on increase of the longitudinal velocity. Three ships have been used to carry out the research - container ship, car carrier and gas carrier. All tests have been done according to the same procedure, i.e. the bow thruster was activated on ships with lowest horizontal velocities possible. The results are shown in terms of rotational and linear horizontal velocities, what allows to perform the quantitative analysis of the described phenomena.

The results obtained during the described experiments and presented in the paper are an introduction to wider research on different aspects on bow thruster actions. Special attention will be paid to the influence of bow thrusters action on the increase of horizontal velocities. Dependence on different initial velocities, especially rotational speed will be taken into account. All the analyses will give valuable feedback to researchers, masters and pilots on the efficiency and performance of tunnel thrusters during port manoeuvres and thus improve navigational safety.

An added value from the presented research is also a short analysis of pivot point position during a turning manoeuver with the use of bow thruster only. Although in the paper only single - bow thruster force is taken into account, the analysis allows, according to the principles of classical mechanics, for further superposition of forces and calculation of actual pivot point during more complicated manoeuvres.

\section{MODEL TESTS}

All experiments have been carried out with manned models, that are usually used for training in ship handling at Ship Handling Research and Training Centre at the lake Silm near Iława in Poland. The models are equipped with steering and propulsion devices, whit their geometric, kinematic and dynamic characteristics scaled down from corresponding full scale ships.

The tested models are equipped with GPS system, what with RTK reference station, that covers the lake with the exercise areas, gives nominal accuracy of 10 millimetres. The heading is measured with the use of gyrocompass with $0.1^{\circ}$ accuracy. Such a standard of tracking system gives sufficient precision both for position and heading measurements and further for horizontal motion calculations for analyses of the investigated phenomenon.

\section{INVESTIGATED SHIPS}

To investigate the described phenomenon three ships equipped with bow thrusters and representing different ship types have been selected for the experiments. Tests have been carried out with the use of manned models build to a scale of 1:24. Principal particulars of tested ships with details of bowthruster are presented in tables below.

\section{Very Large Container Ship}

Single-screw, $10000+$ TEU container ship has been chosen for experiments. Principal particulars of this ship are presented in Table 1. The ship is equipped with bowthruster of $3000 \mathrm{~kW}$ power and thrust of 38 tons, which in full load condition gives possibility to carry out all port operation without tug assistance up to approx. 20 knots.

Table 1. Principal particulars of tested VLCS

\begin{tabular}{|l|c|c|}
\hline & Full scale & Model scale \\
\hline Length overall (m) & 372.00 & 15.50 \\
Length between perpendiculars (m) & 351.84 & 14.66 \\
Beam (m) & 43.00 & 1.79 \\
Draft (m) & 14.50 & 0.60 \\
Displacement (t) & 155200 & 10.95 \\
Block coefficient & 0.690 & 0.690 \\
Bowthruster diameter (mm)* & 3600 & 150 \\
Bowthruster power (kW) Bowthruster & 3000 & - \\
thrust (tons) & 38 & - \\
Bowthruster thrust (N) & - & 27 \\
Position of bow thruster (xBT/LPP) & 0.447 & 0.447 \\
\hline
\end{tabular}




\section{Pure Car and Truck Carrier}

The car carrier chosen for the tests is a 7000 CEU ship with dimensions presented in Table 2. The ship is single-screw and is equipped with bow and stern thruster. Due to large windage area the ship is equipped with rather strong bowthruster units of $2000 \mathrm{~kW}$ power and 30 tons of thrust each.

Table 2. Principal particulars of tested PCTC

\begin{tabular}{|l|c|c|}
\hline & Full scale & Model scale \\
\hline Length overall (m) & 218.85 & 9.12 \\
Length between perpendiculars (m) & 205.00 & 8.54 \\
Beam (m) & 30.50 & 1.27 \\
Draft (m) & 12.09 & 0.50 \\
Displacement (t) & 62450 & 4.41 \\
Block coefficient & 0.774 & 0.774 \\
Bowthruster diameter (mm)* & 2880 & 120 \\
Bowthruster power (kW) & 2000 & - \\
Bowthruster thrust (tons) & 30 & - \\
Bowthruster thrust (N) & & 21 \\
Position of bow thruster (xBT/LPP) & 0.439 & 0.439 \\
\hline
\end{tabular}

\section{LNG carrier}

Twin azimuth units, $150000 \mathrm{~m} 3$ LNG carrier has been used for the experiments. Table 3 shows the principal particulars of the model. Extremely powerful bowthruster of $9000 \mathrm{~kW}$ and a total thrust of 125 tons is used mostly in cooperation with azimuth thrusters, what gives extraordinary manoeuvring abilities at low speeds.

Table 3. Principal particulars of tested LNG carrier

\begin{tabular}{|l|c|c|}
\hline & Full scale & Model scale \\
\hline Length overall (m) & 277.20 & 11.55 \\
Length between perpendiculars (m) & 272.00 & 11.33 \\
Beam (m) & 43.20 & 1.80 \\
Draft (m) & 12.00 & 0.50 \\
Displacement (t) & 113500 & 8.01 \\
Block coefficient & 0.786 & 0.786 \\
Bowthruster diameter (mm)* & 3600 & 150 \\
Bowthruster power (kW) & 9000 & - \\
Bowthruster thrust (tons) & 125 & - \\
Bowthruster thrust (N) & - & 89 \\
Position of bow thruster (xBT/LPP) & 0.429 & 0.429 \\
\hline
\end{tabular}

* - in all cases, bow thruster diameter not from actual ship, but according to available tube diameters in model scale

\section{TEST PROCEDURE}

Practically, the purpose of the thruster test is to determine the turning qualities using thruster(s) with the ship dead in the water or running at a given speed. This test is essential to provide the information necessary to comply with IMO Resolution A601(15) (IMO, 1987), which lists information to be available on the bridge in the Pilot Card, Wheelhouse Poster, and Manoeuvring Booklet.
Additional, utilitarian aim of the tests might be obtaining data that can also be useful in future ship and tunnel thruster designs.

Some suggestions and guidelines for the thruster test have been given by Journee, Pinkster (2002) and by SNAME (2015) and can be summarized as follows:

1. With the ship dead in the water at the heading prescribed in the trial agenda and the engine set to "stop engine", start the data acquisition.

2. Order the bow thruster(s) to full thrust.

3. When the thruster(s) operate over 10 minutes or the ship's heading reaches 300 , the test is complete.

4. The ship is brought back to a dead in the water condition at the desired heading, in readiness for the subsequent test (reverse bow thruster).

The same procedure could be applied using an initial forward speed designated in the trial agenda (starting point being a stable prescribed speed). Headings for left and right turns should be the same.

With the ship in trial ballast condition, it should be noted that reduced thrust may result unless the thruster is not properly submerged. The thruster should be submerged so that its axis is at a depth of at least 0.8 times the thruster diameter. Bow thruster tests for dry cargo ships in the trial ballast condition are severely influenced by sea and wind and should be conducted only in protected areas or in the open sea when the sea conditions are exceptionally smooth (SNAME, 2015).

In case of presented tests, the experiments have been done in full load condition in windless and waveless conditions.

\section{TEST RESULTS}

During the tests, the position of centre of gravity, the heading and the speed over ground and water have been measured. Based on this data, the rate of turn, longitudinal and lateral velocities and pivot point position have been calculated.

Most common in hydrodynamics coordinate system as in Figure 1 has been used during analyses. This denotes an earth-fixed system Ox0y0z0 and a ship-fixed system Mxyz with the origin at midship, where $\psi$ is the ship heading.

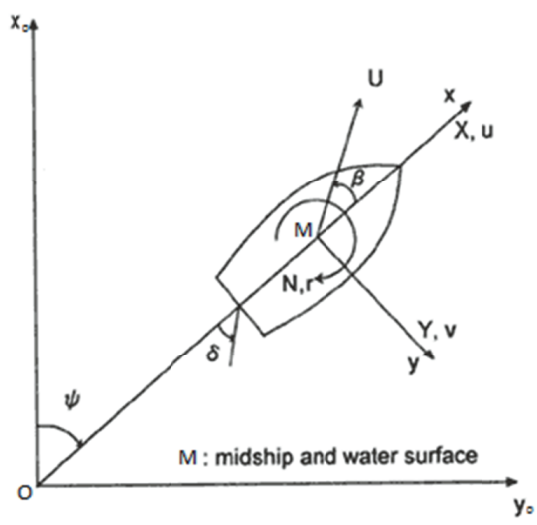

Fig. 1. Coordinate system used during analyses 
All results presented below are in model scale dimensions. The test for container vessel and LNG carrier have been done for more than 120 seconds, what corresponds to $10 \mathrm{~min}$ in full scale, while for PCTC for 82 second only $(6.7 \mathrm{sec}$. in full scale). This exception however does not influence the total performance of the ship during the test and gives sufficient information on the overall tendencies.

\section{HEADING AND HEADING RATE}

Figures below show changes in heading and heading rate calculated from GPS and gyrocompass. Heading rate, as expected can be divided into two phases. Initial one, when the ship accelerates in turn with increasing rate of turn and the second phase, when the rate of turn is approximately constant and the heading is changing nearly linear.

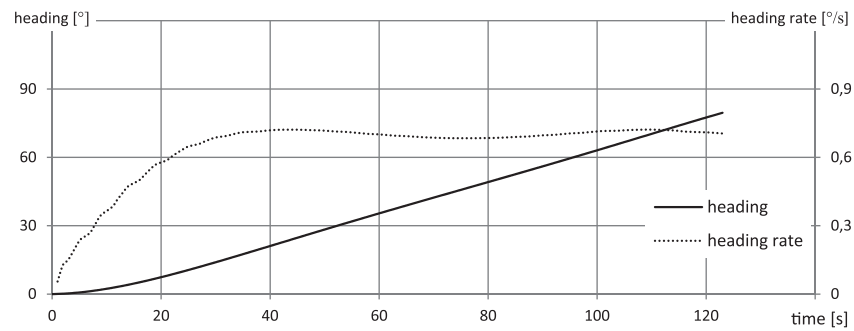

Fig. 2. Container ship heading and heading rate for thruster test with $100 \%$ bow thruster power

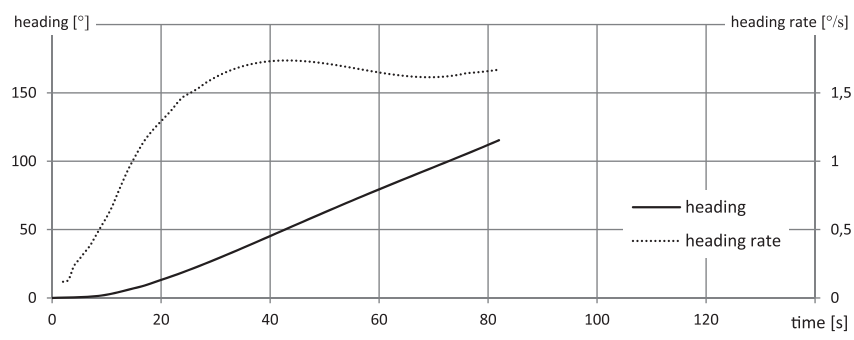

Fig. 3. PCTC heading and heading rate for thruster test with $100 \%$ bow thruster power

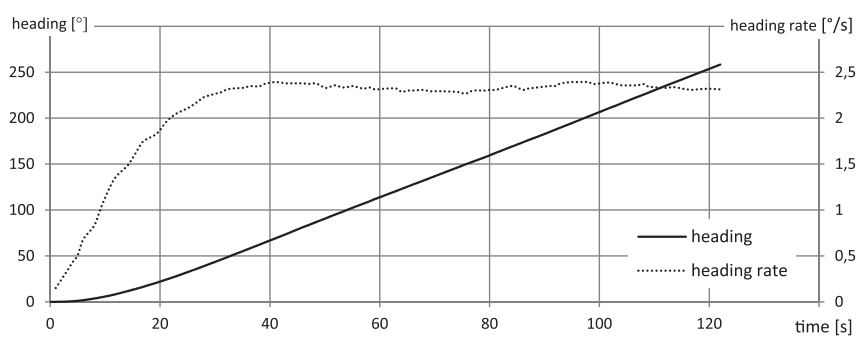

Fig. 4. LNG carrier heading and heading rate for thruster test with 100\% bow thruster power

\section{LINEAR VELOCITIES}

Figures 5-7 show longitudinal and lateral velocities of centre of gravity calculated from the position received from the GPS. These velocities are presented in ship-fixed coordinate system. Some initial speed, especially in case of lateral velocity, is visible in all presented tests. It does not influence however the total tendencies in changes of the horizontal motions.

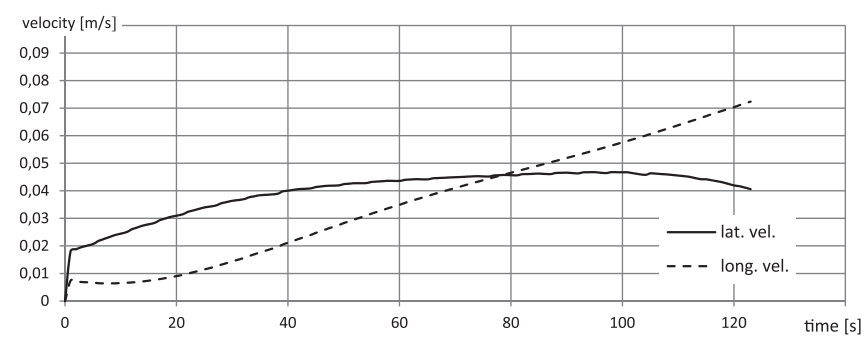

Fig. 5. Container ship lateral and longitudinal velocity for thruster test with 100\% bow thruster power

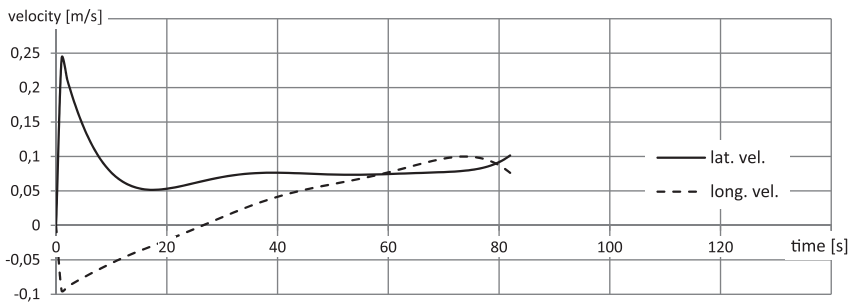

Fig. 6. PCTC lateral and longitudinal velocity for thruster test with $100 \%$ bow thruster power

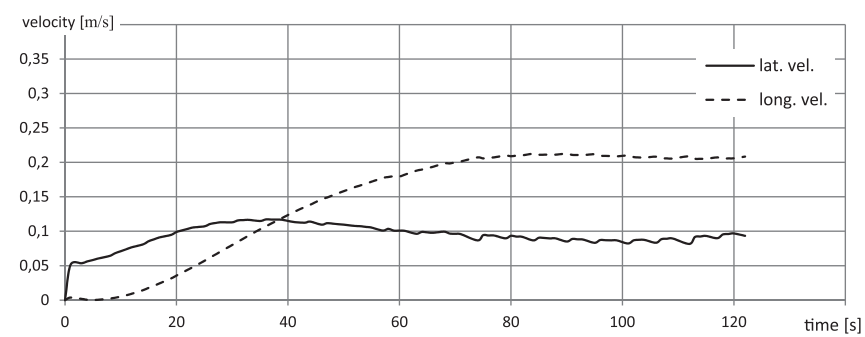

Fig. 7. LNG carrier lateral and longitudinal velocity for thruster test with $100 \%$ bow thruster power

\section{PIVOT POINT}

Longitudinal position of pivot point has been calculated according to the most common equation $x_{P P}=\frac{-v}{r}$ In the following figures the longitudinal position has been nondimensionalised by the length between perpendiculars. It may be seen that the pivot point moves in the initial phase from a point far behind the aft to a point around $20-30 \%$ of 
LPP behind the midship.

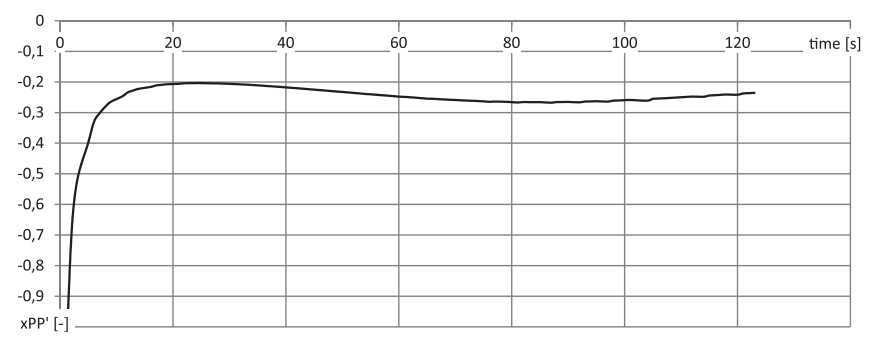

Fig. 8. Dimensionless longitudinal position of pivot point on container ship for thruster test with 100\% bow thruster power

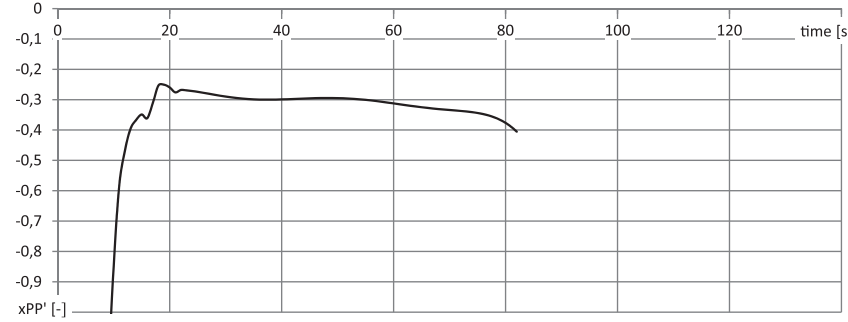

Fig. 9. Dimensionless longitudinal position of pivot point on PCTC for thruster test with $100 \%$ bow thruster power

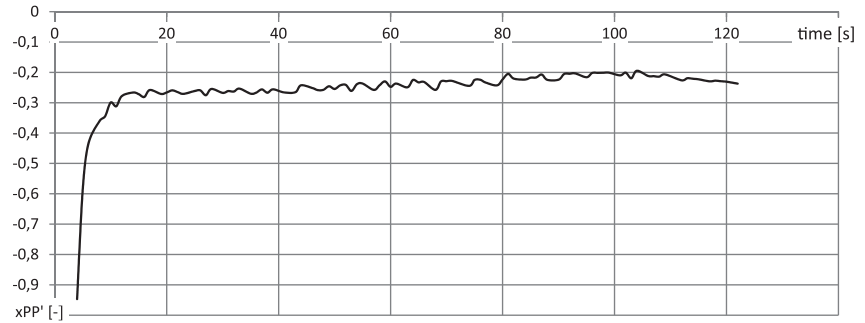

Fig. 10. Dimensionless longitudinal position of pivot point on LNG carrier for thruster test with $100 \%$ bow thruster power

\section{DISCUSSION AND CONCLUSIONS}

In the paper, initial results from a project on different aspects of bow thruster performance have been presented. Standard bow thruster test on three ships has been carried out to find out the influence of bow thruster action on increase of ship longitudinal velocity.

As can be seen from the analyses, the constant rate of turn is achieved after around 30-40 seconds (2.5 to $3.5 \mathrm{~min}$ in full scale) from the bow thruster start for all ships. Afterwards the rotational velocity stabilizes and remains more or less constant.

Also linear velocities have the same tendencies for all tested ships. Except rather large initial velocity for the PCTC, the lateral velocity for other ships increases to some value and remains constant. The same is visible in case of longitudinal velocity. Because of the centrifugal force, the speed increases to a certain value and later due to ship resistance stabilizes.

The best information on the phenomena of the longitudinal velocity increase due to the action of bow thruster gives the test carried out with LNG carrier. Because of very powerful bow thruster the initial phase of acceleration both in rotational and linear velocities is relatively short and thus constant values of those velocities are achieved in a short time.

The pivot point in thruster tests, that have been carried out, moves from very far aft to around $20-30 \%$ of the length between perpendiculars behind the midship. The position of pivot point is actually a result of both rotational and longitudinal velocities. Especially the longitudinal motion influences the reduction of distance between the pivot point and the midship.

The information on the actual rotational and linear velocities and on actual pivot point position should be taken into account during planning and execution of manoeuvres and passages in restricted waters, e.g. in harbours or in narrow channel or rivers.

Additional analyses of influence of bow thruster action on longitudinal velocity and position of pivot point will follow.

\section{REFERENCES}

1. Abramowicz-Gerigk, T. (2008). Experimental study on the hydrodynamic forces induced by a twin-propeller ferry during berthing. Ocean Engineering, 35(3-4), pp.323-332

2. Artyszuk, J. (2003). Ship sway/yaw motions while turning with bow lateral thruster. 15th International Conference on Hydrodynamics in Ship Design, Safety and Operation HYDRONAV 2003, Gdańsk

3. Artyszuk, J. (2010). Pivot point in ship manoeuvring. Scientific Journals of Maritime University of Szczecin, 20(92), pp.13-24

4. Brix, J. (1993). Manoeuvring technical manual. 1st ed. Hamburg: Seehafen Verlag GmbH, Germany

5. Chislett M.S., Björheden O. (1966). Influence of Ship Speed on the Effectiveness of a Lateral - Thrust Unit. Report no. 8, Hydro- og Aerodynamisk Laboratorium, Kgs. Lyngby, Denmark

6. Gierusz, W. (2016). Simulation model of the LNG carrier with podded propulsion, Part II: Full model and experimental results. Ocean Engineering, 123, pp.28-44

7. IMO (1987). Resolution A.601(15) Provision and display of manoeuvring information on board ships

8. Journee J.M.J., Pinkster J. (2002). Introduction in ship hydromechanics. Delft University of Technology, the Netherlands 
9. Quadvlieg F.H.H.A. and Toxopeus S.L. (1998). Prediction of crabbing in the early design stage. In: Practical Design of Ships and Mobile Units. Elsevier Science B.V., pp.649-654

10. Reichel, M. (2017). Prediction of manoeuvring abilities of 10000 DWT pod-driven coastal tanker. Ocean Engineering, 136, pp.201-208

11. SNAME (2015). Guide for Sea Trials (Progressive Speed, Maneuvering, and Endurance). SNAME Technical and Research Bulletin 3-47

\section{ACKNOWLEDGEMENTS}

Research presented in this paper has been financed from statutory fund of Ship Handling Research and Training Centre, Foundation for Safety of Navigation and Environment Protection.

\section{CONTACT WITH THE AUTHOR}

Maciej Reichel e-mail:maciejr@portilawa.com

Ship Handling Research and Training Centre 14-200 Iława-Kamionka Poland 